\title{
Análisis de los productos turísticos: caso Península de Santa Elena, Ecuador
}

\section{Analysis of tourism products: the case of Santa Elena Peninsula, Ecuador}

Rafael Francisco Arce Bastidas ${ }^{1}$, Erick Suárez Domínguez ${ }^{2}$, Elisa Verónica Solís Argandoña ${ }^{3}$, Nadia Argudo Guevara $^{4}$

INFORMACIÓN DEL

\section{ARTÍCULO}

Fecha de recepción: 11 de Septiembre de 2020 .

Fecha de aceptación: 26 de Noviembre de 2020.

\footnotetext{
${ }^{1}$ Máster en Planificación Territorial y Gestión Ambiental, Universidad De Barcelona. Docente-investigador, Universidad de Guayaquil-Ecuador E-mail: rafael.arceb@ug.edu.ec

Código ORCID:

https://orcid.org/0000-0001-8013-4217
}

${ }^{2}$ Máster en Management Internacional, Université D'Angers. DocenteInvestigador, Universidad de Guayaquil-Ecuador.

E-mail: erick.suarezdo@ug.edu.ec

Código ORCID:

https://orcid.org/0000-0003-1046-8259

3 Magister en Gestión Turística, Universidad Tecnológica América Docente- investigadora, Universidad de Guayaquil -Ecuador.

E-mail: elisa.solisa@ug.edu.ec

Código ORCID:

https://orcid.org/0000-0001-8673-0618

${ }^{4}$ Master en Management et Developpement du Tourisme, de I'Hotellerie, de la Restauration et des Loisirs Specialite Chef de Projet, Conseil en Developpement Université D'Angers. Docente-investigadora Universidad de Guayaquil-Ecuador. E-mail: nadia.argudog@ug.edu.ec

Código ORCID:

https://orcid.org/0000-0003-2272-1450

CITACIÓN: Arce Bastidas, R.F., Suárez Domínguez,E., Solís Argandoña, E.V. \& Argudo Guevara, N.(2020). Análisis de los productos turísticos: caso Península de Santa Elena, Ecuador. Podium, 38, 139-158. doi:10.31095/podium.2020.38.9

ENLACE DOI:

http://dx.doi.org/10.31095/podium.202 0.38 .9

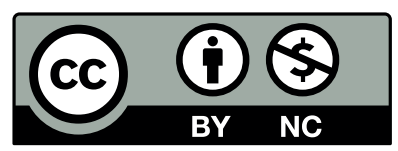

\section{Resumen}

La Península de Santa Elena (PSE) como destino turístico litoral del Ecuador, posee una variedad de atractivos que constituyen productos turísticos poco analizados, presentándose así la necesidad de evaluarlos, ya que, son parte de los destinos relevantes del Mundo Costa que comercializa el país en el extranjero. Esta investigación tiene un enfoque cualitativo y utiliza fuentes secundarias, además de la herramienta de análisis FODA, las cuales permitieron distinguir las variables que definen al portafolio de productos turísticos que oferta la PSE. Se concluye que, para la PSE como destino de Sol y Playa, es difícil salir de ese encasillamiento, haciendo complicada la adaptación de productos turísticos nuevos, debido a la poca gestión pública y baja valorización de los recursos naturales y culturales, persistiendo una inadecuada estructuración, lo que repercute en la búsqueda de nuevos mercados.

\section{Palabras Clave:}

Destino de Sol y Playa, Península de Santa Elena, Destino Turístico, Oferta Turística, Producto Turístico, Gestión Pública.

Clasificación JEL: Z33.

\begin{abstract}
The Santa Elena Peninsula (PSE as peer abbreviation in Spanish) is a coastal tourist destination in Ecuador. It has a variety of attractions that have not been fully analyzed as tourist products. It needs analysis and evaluation, in as much as it is a part of the "Coast World" destination that is promoted by the country at international markets. The research has a qualitative focus; it uses secondary sources as well as the SWOT analysis tool. This tool permits distinguishing variables that define the tourism product portfolio which is offered by the Santa Elena Peninsula. It is concluded that it is difficult to avoid typecasting the PSE as a Sun and Beach destination. This makes it hard to adapt new tourism products; there is but poor public-ity management and low natural and cultural resource valuation; tourism product structuring is inadequate, which affects new market search.
\end{abstract}

\section{Keywords:}

Sun and sea destination, Santa Elena Peninsula, Tourist Destination, Tourist Offer, Tourism Product, Public Managemen.

JEL Classification: Z33.

$$
139
$$

PODIUM No. 38, Diciembre 2020, pp. 139-158

(C) Universidad Espíritu Santo - UEES

ISSN: 1390-5473 e-ISSN: 2588-0969 


\section{Introducción}

El turismo durante las seis últimas décadas ha experimentado una continua expansión y diversificación, convirtiéndolo en uno de los sectores económicos de mayor envergadura y crecimiento del mundo. Los arribos de turistas internacionales a escala mundial han pasado de 25 millones en 1950 a 1.235 millones en 2016. Asimismo, los ingresos por turismo internacional obtenidos por los destinos de todo el mundo han pasado de USD 2.000 millones en 1950 a 1.220.000 millones en 2016 (UNWTO, 2017). Por lo tanto, es un sector clave para los países, ya que trae consigo progreso socioeconómico, a través de la creación de puestos de trabajo y de empresas, la generación de ingresos de exportación y la ejecución de infraestructuras. Tal es el caso de Ecuador, que en el año 2017 recibió 1'617.914 turistas generando un ingreso para el país de USD 1.204,5 millones según manifestó el MINTUR (2018). En este sentido, los ingresos provenientes del turismo para Ecuador son significativos en su crecimiento económico (Lambogglia, 2014), llegando a ser uno de los rubros importantes en la economía del país. En adición, para el año 2014 el Ministerio de Turismo indicó que hubo un incremento del 19\% respecto al año 2013, contribuyendo con USD 1,5 billones a la economía del país, equi-valente al 5\% del Producto Interno Bruto (PIB) logrando ser el tercer sector económico no petrolero del país (MINTUR, 2015). Sin embargo, en Ecuador no se observa una cataloga-ción que permita distinguir las caacterísticas específicas de lo que es un producto y atractivo turístico (MINTUR, 2013). De esta manera, se evidencia un déficit de estructuración y diversificación del producto turístico, así como de la estacionalidad, como problemas irresueltos para el turismo en el país (Forteza, Lam, y Ledesma, 2017). Además, la deficiencia en normas, certificación y fiscalización de oferta turística ha conllevado a una escasa diferenciación del país e informalidad en los servicios turísticos, según lo dio a conocer la Comisión Económica para América Latina y el Caribe-CEPAL (2015).

En este sentido, el espacio litoral ecuatoriano se ha convertido en los últimos años en una región de desarrollo tanto del turismo interno ${ }^{5}$ debido a que las playas se vuelven atractivas e invitan a movilizar a los ecuatorianos residentes en diversos países (Prieto, 2011) como para el turismo receptor ${ }^{6}$ del cual un $10,2 \%$ en el año 2011 hizo actividades de Sol y Playa (MINTUR, 2012). De la misma forma, es importante considerar que desde el punto de vista de la oferta de cara a la conservación y, muy especialmente, a la puesta en valor del patrimonio, es necesario analizar mejor la oferta turística (Ibarra, 2001), ya que la formulación del producto involucra el análisis y la evaluación de los elementos del producto y la identificación de productos turísticos totales del rango de posibilidades disponibles en cualquier

\footnotetext{
5 Turismo interno: El turismo interno incluye las actividades realizadas por un visitante residente en el país de referencia, como parte de un viaje turístico interno o de un viaje turístico emisor (UNWTO, 2018).

${ }^{6}$ Turismo receptor: Engloba las actividades realizadas por un visitante no residente en el país de referencia, como parte de un viaje turístico receptor (UNWTO, 2018).
} 
destino (Middleton, 1989).

La Península de Santa Elena (PSE) es un destino turístico ubicado en el espacio más occidental de la costa ecuatoriana (ver Figura 1) y que, por sus atributos biofísicos, permite al visitante disfrutar de una variedad de productos turísticos (GAD Provincial Santa Elena, 2015). Antes de la llegada de los españoles, la PSE era un conglomerado muy próspero e importante y se denominaba Sumpa, palabra que en lengua Chimú significa: Punta. Este legado ancestral ha dado al territorio un valor cultural sustancial debido a que en esta zona se encontraba la cultura Las Vegas considerada como unos de los centros de civilización más antigua de América (GAD cantonal Salinas, 2014; Stothert,1985). En este territorio cohabitan unas 308.693 personas de las cuales $55 \%$ corresponden a población urbana (INEC, 2010), posee una superficie de $3.762,80 \mathrm{Km}^{2}$. Su potencial económico está ligado al sector agrícola y pecuario, la acuicultura, la pesca, el comercio y en especial a la actividad turística. En sus $160 \mathrm{Km}$ de playas, se encuentran importantes balnearios como Salinas, San Pablo, Punta Blanca, Montaña entre otros (GAD Provincial Santa Elena, 2015).

La PSE posee una gran cantidad de atractivos que no cuentan con un análisis adecuado a nivel de identificación $\mathrm{y}$ estructuración de la oferta de productos turísticos en consecuencia, vuelve compleja la posibilidad de atraer nuevos turistas, aun cuando es un destino relevante en el Mundo Costa $^{7}$ (MINTUR, 2009).

Por lo tanto, el presente trabajo tiene como objetivo evaluar la oferta de productos turísticos que posee la PSE, considerando la importancia que tiene para el Ecuador su comercialización turística en el extranjero.

\section{Revisión de literatura}

\section{Producto turístico}

El producto turístico es una colección

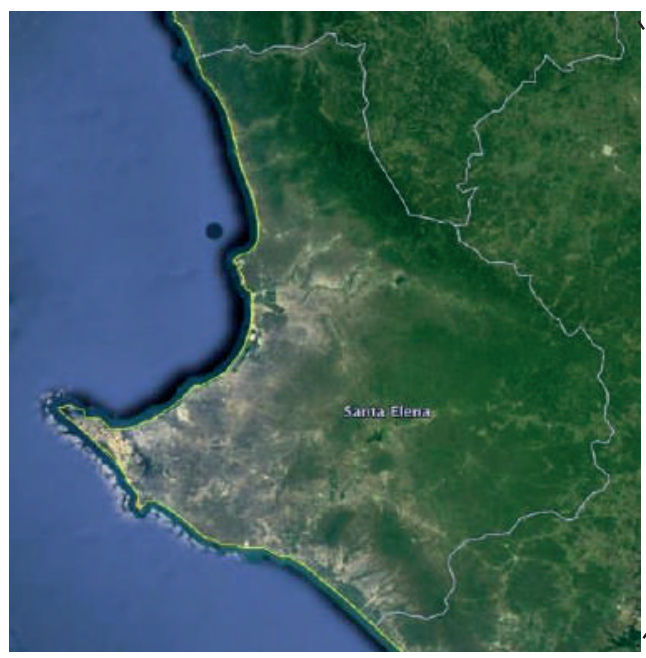

Figura 1. Localización geográfica de la Península de Santa Elena. Fuente: Google Earth Pro.

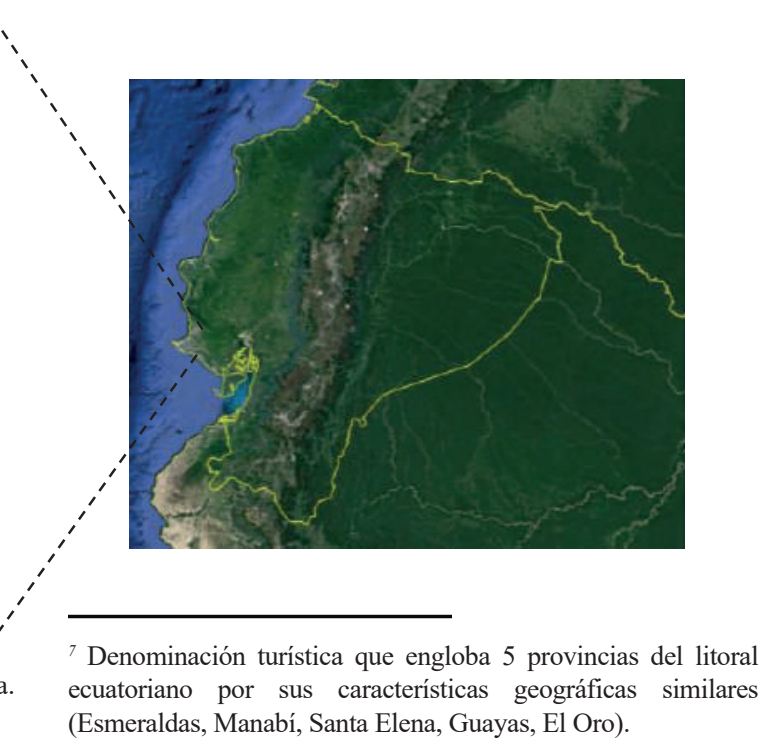

141

PODIUM No. 38, Diciembre 2020, pp. 139-158

(C) Universidad Espíritu Santo - UEES

ISSN: 1390-5473 e-ISSN: 2588-0969 
de características físicas o elementos tangibles (Acerenza, 2004; Cárdenas, 2008; Medlik y Middleton, 1973; Milio, 2004; Revilla, Gil, López, y Rey, 2004) y servicios o elementos intangibles (Acerenza, 2004; Cárdenas, 2008; Jefferson y Lickorish, 1991; Medlik et al., 1973; Milio, 2004; Revilla et al., 2004) que se ordenan de forma que ofrezcan beneficios a los clientes (Milio, 2004; Revilla et al., 2004), resultando en la satisfacción del turista (Acerenza, 2004; Jefferson y Lickorish, 1991; Milio, 2004). Es decir, que el producto turístico es el resultado de un proceso de producción al igual que un producto de cualquier tipo de industria, ya que su dinámica de manufactura involucra elementos tangibles e intangibles que actúan como insumos primarios e intermedios hasta generar un resultado final que se refleja en la experiencia que tuvo el turista (Smith, 1994) y aunque existe esta estrecha relación entre producto turístico y experiencia no son lo mismo (Salinas y Medina, 2009).

Según McKercher (2016) un producto turístico se puede clasificar en familias de acuerdo con la necesidad del turista, así los productos turísticos se pueden agrupar en uno de los cinco tipos según las necesidades que se satisfacen: placer, búsqueda personal, esfuerzo humano, naturaleza y negocios, de estas necesidades se crean 27 familias de productos, las cuales a su vez se subdividen en 90 tipos de subproductos que describen la oferta posible de productos turísticos disponibles de un mercado.

La tipología de productos turísticos desde el enfoque científico no ha podido lograr una estandarización en la terminología utilizada, de manera que se abarcará el tema desde el enfoque le dan los agentes que gestionan el turismo tanto a nivel nacional como internacional.

Variables que definen y componen el producto turístico

La clasificación de productos turísticos no solo le ha concernido a la sociedad científica, sino también a instituciones públicas nacionales $\mathrm{e}$ internacionales encargadas de la gestión del turismo. Una de las más importantes fue la realizada por la Organización Mundial del Turismo (OMT) y la Comisión Europea de Viaje que clasifican a los productos en ocho tipos: bienestar y salud, sol y playa, patrimonio y cultura, naturaleza, festividades locales, negocios, moda y compras y aventura y deportes extremos (UNWTO/ETC, 2011).

Por otro lado, instituciones gubernamentales como el Servicio Nacional de Turismo de Chile (SERNATUR, 2015), definen el producto turístico como todo bien tangible e intangible consumido por un segmento de mercado específico, compuesto por elementos como el atractivo turístico, los servicios turísticos, la infraestructura, la comunidad local y la percepción- imagen-emoción. Sin embargo, esta institución señala que la percepciónimagen-emoción, se manifiestan al momento que se consume el producto como tal, lo que significa que más allá de ser un elemento del producto podría ser un condicionante transversal en el proceso de entrega del producto, así como un indicador 
para medir la calidad del mismo, mientras que, los tres iniciales se enfocan en aspectos esenciales para el diseño del producto y responden a las necesidades de los

Tabla 1.

Variables de los Productos Turísticos a partir de su definición

\begin{tabular}{lll}
\hline Autor & Definición & Variables
\end{tabular}

Medlik y Middleton, 1973

Jefferson y Lickorish, 1991

Cárdenas, 2008

Milio, 2004

Revilla et al, 2004

Acerenza, 2004
El producto turístico es un conjunto de actividades, servicios y beneficios que constituyen la totalidad de la experiencia turística.

El producto turístico es una colección de características físicas y de servicio junto con asociaciones simbólicas con las cuales se espera cumplir con los deseos y necesidades de los compradores y de forma más sucinta, el producto turístico, es una actividad satisfactoria en un destino deseado.

El producto turístico está conformado por el conjunto de bienes y servicios que se ofrecen al mercado -para confort material o espiritual - en forma individual o en una gama muy amplia de combinaciones resultantes de las necesidades, requerimientos o deseos de un consumidor al que llamamos turista.

Producto turístico es la combinación de bienes y servicios, de recursos e infraestructuras que se ordenan de forma que ofrezcan beneficios a los clientes, para que consigan satisfacer sus necesidades y expectativas y que estén disponibles para ser consumidos en el momento preciso.

Producto turístico es la combinación de elementos tangibles e intangibles que generan utilidades o beneficios al cliente en forma de experiencias fuera de su lugar habitual de residencia o trabajo.

El producto turístico no es más que un conjunto de prestaciones, materiales e inmateriales que se ofrecen con el propósito de satisfacer los deseos y las expectativas de los turistas.
Intangible: actividades, servicios, beneficios.

Experiencia: experiencia turística

Intangible: servicio.

Tangible: características físicas.

Satisfacción Necesidad: cumplir con los deseos y necesidades, actividad satisfactoria.

Intangible: servicios.

Tangible: bienes.

Satisfacción necesidad: deseos del consumidor

Intangible: servicios. Tangibles: bienes, recursos, infraestructura.

Satisfacción necesidad: satisfacer necesidades y expectativas.

Intangible: elementos intangibles Tangibles: elementos tangibles. Satisfacción necesidad: utilidad, beneficio

Experiencia: forma de experiencias Intangible: prestaciones inmateriales

Tangibles: prestaciones

materiales

Satisfacción necesidad: satisfacer los deseos

Fuente: Elaboración propiava partir de las definiciones de varios autores.

\section{3}

PODIUM No. 38, Diciembre 2020, pp. 139-158

(C) Universidad Espíritu Santo - UEES

ISSN: 1390-5473 e-ISSN: 2588-0969 
Por lo tanto, las definiciones sugieren que el producto turístico es un "todo", lo que hace complejo el análisis del mismo y aunque se lo puede entender como la agrupación de dos variables claramente identificables esto es; tangibles e intangibles, es posible que las variables intangibles sean mucho más significativas para el visitante debido a que el producto turístico suele ser percibido como un generador de experiencia mientras viaja (recuerdos, ideas, imágenes, historias, etc.) lo que le permite satisfacer sus deseos de realizar un viaje por turismo, lo que sí es importante considerar es que esta percepción, suele afectar el estado de satisfacción ya que es el resultado evaluativo de la experiencia del viaje cuya medición es una tarea compleja influenciada por varios factores como: el área del destino, sus instalaciones, la limpieza, las atracciones, la geografía del territorio, el clima, etc. (Pizam, Neumann, y Reichel, 1978).

\section{Oferta de productos turísticos de Ecuador}

Respecto a la oferta turística en Ecuador, el Plan Estratégico de Desarrollo de Turismo Sostenible Para Ecuador -PLANDETUR 2020- es el instrumento rector del Ministerio de Turismo (MINTUR, 2020) que examina la oferta turística de Ecuador a profundidad, el cual acoge la idea de producto turístico como una propuesta de viaje, estructurada desde los recursos (playa, montaña, bosque, etc.), a la que se incorporan servicios turísticos (transporte, alojamiento, guías de viajes, etc.) presentado a los productos turísticos con el término de portafolio de productos o mix de productos los que han sido conformados por la línea de producto y estos a su vez desagregados en productos específicos de acuerdo con cada línea de producto.

En este sentido el MINTUR (2007)

Tabla 2

Línea de productos turísticos y variedades de productos específicos

\begin{tabular}{|c|c|c|c|}
\hline Línea de producto & Producto específico & Línea de producto & Producto específico \\
\hline Circuitos generales & Circuitos generales & Ecoturismo y turismo & Parques nacionales \\
\hline Sol y playa & sol y playa & de naturaleza & Reservas y bosques privados \\
\hline Turismo comunitario & Turismo comunitario & & $\begin{array}{l}\text { Ríos, lagos, lagunas y cascadas } \\
\text { Observación de flora y fauna }\end{array}$ \\
\hline \multirow[t]{8}{*}{ Turismo cultural } & $\begin{array}{l}\text { Patrimonios naturales } \\
\text { y culturales }\end{array}$ & $\begin{array}{l}\text { Turismo de deportes } \\
\text { y aventura }\end{array}$ & Deportes terrestres \\
\hline & Mercados y artesanías & & Deportes fluviales \\
\hline & Gastronomía & & Deportes aéreos \\
\hline & Fiestas populares & & Deportes acuáticos \\
\hline & $\begin{array}{l}\text { Mercados y artesanías } \\
\text { Shamanismo } \\
\text { Turismo urbano }\end{array}$ & Turismo de salud & $\begin{array}{l}\text { Termalismo } \\
\text { Medicina ancestral } \\
\text { SPA's }\end{array}$ \\
\hline & Turismo arqueológico & Agroturismo & Haciendas, fincas y plantaciones \\
\hline & $\begin{array}{l}\text { CAVE, científico, } \\
\text { académico, voluntario } \\
\text { y educativo }\end{array}$ & $\begin{array}{l}\text { Turismo de convenciones } \\
\text { y congresos }\end{array}$ & $\begin{array}{l}\text { Reuniones, incentivos, } \\
\text { conferencias, exposiciones y ferias }\end{array}$ \\
\hline & $\begin{array}{l}\text { Haciendas históricas } \\
\text { Parques temáticos }\end{array}$ & Turismo de cruceros & Cruceros \\
\hline
\end{tabular}

Fuente: Información obtenida del PLANDETUR 2020. 
identifica once líneas de productos turísticos (ver Tabla 2): Circuitos generales, 2) Sol y playa, 3) Turismo comunitario, 4) Turismo cultural, 5) Parque temáticos, 6) Ecoturismo y turismo de naturaleza, 7) Turismo de deportes y aventura, 8) Turismo de salud, 9) Agroturismo, 10) Turismo de Convenciones y Congresos (MICE), y 11) Cruceros.

Adicionalmente, el Plan Integral de Marketing Turístico de Ecuador -PIMTEotro instrumento del MINTUR relacionado a los productos turísticos que segmenta el portafolio de productos turísticos del PLANDETUR 2020 de acuerdo con la relevancia del producto turístico en función de su promoción (ver Tabla 3 ) así se tienen: Productos claves o estrellas, de consolidación o estratégicos y de oportunidad (MINTUR, 2009).

En consecuencia, los productos turísticos en Ecuador están definidos no solo en términos de líneas generales, sino que también por la relevancia que tienen los productos en función de su promoción. La clasificación por la línea de producto permite agregar tantos tipos de turismo como sean posibles mientras correspondan o mantengan características similares a la línea original del producto. Asimismo, es posible determinar la relevancia del producto turístico en función de su importancia para la promoción, ya sea porque aportan valor añadido al turismo, un valor mediano de interés para el país o bien sirven porque permiten atraer nuevos nichos de mercado o segmentos específicos, lo que va a incidir en la prioridad al momento de disponer de recursos para la promoción de determinado producto turístico en el país. En tanto, la vaguedad sobre la idea de producto turístico está presente en ambos instrumentos siendo que como se presentan las líneas de productos se podrían entender también como modalidades turísticas (Ibáñez y Rodríguez, 2012) y no como productos turísticos en

Tabla 3.

Productos turísticos según su relevancia en función de la promoción (resumen)

\begin{tabular}{|c|c|}
\hline Tipo o & Relevancia para la promoción \\
\hline ive & $\begin{array}{l}\text { Productos que aportarán mayor valor añadido a la actividad turística del país, por su mayor } \\
\text { atractivo, potencialidad e idoneidad para Ecuador. Su promoción debe estar principalmente } \\
\text { centrada en torno a su desarrollo. } \\
\text { Están esta categoría: El Turismo cultural, ecoturismo o turismo de naturaleza y el turismo de } \\
\text { deportes y aventura }\end{array}$ \\
\hline $\begin{array}{l}\text { Productos de } \\
\text { consolidación o } \\
\text { estratégicos }\end{array}$ & $\begin{array}{l}\text { Son productos que, aunque importantes para el país, no aportan el valor que aportan los productos } \\
\text { clave. Su promoción es estratégica. Están esta categoría: } \text { El turismo comunitario, MICE y el } \\
\text { turismo de cruceros. }\end{array}$ \\
\hline $\begin{array}{l}\text { Productos de } \\
\text { oportunidad }\end{array}$ & $\begin{array}{l}\text { Productos que no aportan un gran volumen en comparación con los anteriores, pero de interés } \\
\text { para el país para atraer a nichos de mercado o segmentos específicos interesados. La promoción } \\
\text { en estos productos debe ser puntual (de nicho), según surja la oportunidad. Están en esta } \\
\text { categoría: El agroturismo, el turismo de salud, el turismo de sol y playa (observación de } \\
\text { ballenas, surf, entre otros) y el de parques temáticos. }\end{array}$ \\
\hline
\end{tabular}

Fuente: Elaborado a partir del PIMTE 2014. 
sí mismos. Por otro lado, la clasificación presentada en ambos instrumentos correspondientes a los productos turísticos queda incompleta si se considera la definición empleada en el mismo PLANDETUR que estructura al producto turístico bajo tres atributos básicos: atractivo, facilidades y accesibilidad (MINTUR, 2007), la clasificación presentada al parecer solo contempla el atributo del atractivo, dejando de lado los otros atributos de facilidades $y$ accesibilidad. Además, el precio (Mankiw, 2017) es determinante al momento de definir un producto algo que tampoco se ve reflejado en la clasificación empleada, a esto se suma que la clasificación de productos turísticos en PLANDETUR tiende a ser una clasificación basada en las ventajas o bondades del territorio y no en las necesidades del turista (McKercher, 2016). Lo anterior confirma que la idea de producto turístico a nivel de país no está del todo clara o definida, careciendo de una estructura consolidada y fácil de entender y ofertar (CEPAL, 2015; Forteza et al., 2017).

Por otra parte, si se analiza el producto turístico de la PSE en función de la clasificación de la UNWTO, esta quedaría definida como un producto de sol y playa, igualmente analizan-do los componentes de acuerdo con la SERNATUR tales como: atractivo turístico, planta turística, servicios complementarios e infraestructura. Queda claro que la definición de los productos turísticos no solo a nivel de la PSE sino que a nivel del país, se centran exclusivamente en el atractivo turístico dejando de lado en su definición a la planta turística, servicios complementarios e infraestructura. Además, el tipo de producto sol y playa para la planificación de promoción del país (MINTUR, 2009) coloca a la PSE en un escenario de menor consideración por ser un producto de oportunidad. Este mismo enfoque de promoción se extiende a todo el Mundo Costa lo que ha dado como resultado que el litoral ecuatoriano posea una "notoriedad baja" en los canales de comercialización internacional si se lo compara con los otros mundos de acuerdo al MINTUR (2009) como son: Andes, Amazonía o Galápagos, así lo confirma el PIMTE 2014.

\section{Turismo en la Península de Santa Elena}

La región Costa es uno de los territorios turísticos tanto para el viajero nacional como para el extranjero. En el año 2012, la PSE se convirtió en el cuarto destino más visitado por los turistas internacionales en el país, detrás de Quito $58,09 \%$, Guayaquil 37,28\% y Cuenca $11,87 \%$ concentrando el $11,85 \%$ del turismo internacional que arribó al país (MINTUR, 2013).

El turismo en el espacio litoral de Ecuador, conformado por $2.860 \mathrm{~km}$ de longitud, integrando las entradas -golfo, bahías y ensenadas y salientes -península, cabos, puntas-; tiene una larga tradición de uso turístico interno como lugar de sol y playa y se incorpora más tarde y esporádicamente, a la oferta del turismo receptor, que se fortalece luego a través de pro-puestas alternativas relacionadas con el ecoturismo, la observación de mamíferos marinos y aves, aventura y 
deportes. Por su parte, el turismo en la PSE aparece entrado el siglo XX, con un uso recreativo costero incipiente ya que sólo se realiza por moradores asentados en la zona. Esta actividad se vuelve más común en 1911 con la llegada de los ingleses encargados de la extracción petrolera en la península con lo cual se intensificaron las visitas a las playas cercanas, en compañía de sus familias (Perrone, Cajiao, y Burgos, 2009).

Para 1920 parte de la PSE, era conocida como un destino de salud "Viajes a la Península" en el que se visitaban San Vicente, Santa Elena y Salinas avanzando hasta Colonche $\mathrm{y}$ Manglaralto en cómodos automóviles, esto provocó el primer despegue turístico del cantón Salinas (GAD Cantonal Salinas, 2014). Además de los automóviles, en 1936 se establece la vía férrea desde Guayaquil a Salinas, lo que cambia las costumbres guayaquileñas, quienes, en lugar de viajar a la sierra en la temporada invernal, cuando el calor era sofocante en la ciudad empezó a viajar a la península impulsando por primera el turismo en la PSE y en la región (CADS-ESPOL, 2013)

Esto llevó a que, en Salinas, se produzca la construcción de villas y el incremento de edificios para turistas al pie del malecón, como respuesta al boom petrolero de los años 70 de la PSE, otros balnearios de la península como Ballenita y Punta Blanca, en la década de los 80 siguieron el mismo proceso de construcción de segunda residencia donde familias provenientes de Guayaquil encontraban más tranquilidad que en Salinas.
Actualmente, el desarrollo inmobiliario se ha expandido a las demás playas del norte de la península: Capaes, San Pablo, y actualmente San José desarrollando urbanizaciones turístico- residenciales que son ocupadas entre los meses de enero a marzo, en su mayoría, por turistas procedentes de Guayaquil quienes arriban a Santa Elena para el disfrute de sus vacaciones; y en los meses de julio a septiembre, por visitantes que en mayoria provienen de la ciudad de Cuenca y otros sitios de la Sierra, periodo vacacional en esta región (León, 2013).

El turismo es una actividad económica importante para la península, su oferta turística se asocia con actividades recreativas de montaña, naturaleza, cultura, arqueología, entre otras (GAD Cantonal Santa Elena, 2014) pero especialmente la de sol y playa es el principal motivo de visita de los turistas residentes del país con un 51\% (MINTUR, 2012) y se considera como un "Producto de Oportunidad" para los turistas extranjeros provenientes de Colombia y Perú de acuerdo con el PIMTE (MINTUR, 2009). Los meses de temporada alta son de enero a marzo y es cuando se saturan los servicios básicos y los centros poblados se vuelven caóticos.

\section{Metodología}

La presente investigación es de tipo cualitativo, ya que se realizó un análisis de diferentes fuentes para obtener una visión holística del producto turístico que se ha desarrollado hasta el momento en la PSE. En una primera etapa, se clasificó la información bibliográfica ob-tenida de 
fuentes secundarias sobre datos que procedían de instituciones gubernamentales, industriales o individuales (Lafuente Ibáñez y Marín Egoscozábal, 2008) los primeros seis meses del año 2018. La información fue extraída de artículos de revistas indexadas en bases LATINDEX o SCOPUS para definir lo que es un producto y cómo este se relaciona con el turismo, debido a que este conjunto de palabras están presentes en las investigaciones de turismo en la PSE pero no lo que comprenden. Además, de informes oficiales sobre el territorio estudiado como planes de ordenamiento y estudios especializados e información relevante del MINTUR. Asimismo, se consideró la información de organismos internacionales como la UNWTO y la SENATUR de Chile y se incorporó la información de páginas web oficiales de organismos internacionales y nacionales vinculados al turismo.

En una segunda etapa, se realizó un análisis de contenido temático (Schilling, 2006) con el fin de identificar las variables tangibles e intangibles que componen el producto turístico. Dichas variables se utilizaron como base para establecer algunos hallazgos con relación a los productos turísticos del territorio analizado.

En una tercera fase se estructuró un análisis FODA en función de los aspectos tangibles e intangibles del producto turístico con el fin de identificar las fortalezas internas, reconocer las oportunidades y amenazas externas, al tiempo que se abordó las debilidades (Panagiotou, 2003) en la oferta de productos turísticos de la PSE.
Estas fases permitieron realizar la discusión y resultados del estudio por medio de la organización, comparación y análisis de los datos categorizados por medio de matrices de ponderación y descriptivas.

\section{Resultados}

\section{Establecimientos turísticos}

Los establecimientos turísticos forman parte de los productos turísticos ya que se complementan con la oferta de servicios y permiten que la actividad turística se desarrolle adecuadamente. Según datos del MINTUR (2018) se han registrado de manera formal 840 establecimientos relacionados al turismo en la PSE (ver Tabla 4). Sin embargo, existe un sector informal que solo en la Municipalidad del cantón Salinas reportó en el año 2011, un total de 1.711 establecimientos (Martínez, 2014) que representan a vendedores de alimentos y bebidas y personas nacionales o extranjeros que ofrecen servicios varios como: alquiler de sillas y parasoles, equipos para deportes acuáticos, artesanos, entre otros servicios.

Tabla 4.

Establecimientos Turísticos de la PSE

\begin{tabular}{ccc}
\hline Tipo & Cantidad & $\mathbf{\%}$ \\
\hline Alimentos y bebidas & 529 & $62,6 \%$ \\
Alojamiento & 265 & $31,3 \%$ \\
Esparcimiento nocturno & 49 & $5,5 \%$ \\
Transporte turístico & 3 & $0,3 \%$ \\
Recreación familiar & 3 & $0,3 \%$ \\
Total & $\mathbf{8 4 0}$ & $\mathbf{1 0 0 \%}$ \\
\hline Fuente: Elaborado a partir de datos MINTUR (2018).
\end{tabular}

El sector de Alimentos y Bebidas (A\&B) es el que muestra mayor participación en la PSE, contando con más de 500 establecimientos. Esta cifra concuerda 
con la conclusión de Villagómez, Campoverde, y Arteaga (2018), en donde la gastronomía es un atractivo importante para algunas poblaciones de la PSE. Otros estudios sobre A\&B en la PSE como los de Carvache, Torres, y Carvache (2017) y Carvache, Carvache, Macas, y Orden (2018) señalan que la gastronomía complementa el turismo de sol y playa en la gente joven que busca además diversión nocturna y practicar deportes como el surf (Carvache et al., 2017; Carvache et al., 2018). Entre las motivaciones en la PSE más valoradas fueron disfrutar del sol y la playa, seguida de descansar y en la gastronomía la variable más valorada de los restaurantes fue la calidad de las comidas y bebidas, lo que demuestra la importancia de la playa y la riqueza gastronómica del destino (Carvache et al, 2017). Asimismo, los establecimientos de alojamiento se ubican en la segunda posición con 265 establecimientos y teniendo una participación de más del $31 \%$. Las variables más valoradas en cuanto a los servicios de los establecimientos de alojamiento, fue la ubicación de los hospedajes turísticos (Carvache et al, 2017). De esta manera los establecimientos más importantes para Santa Elena son los de A\&B y los alojamientos sumando entre los dos el $93 \%$ de la oferta en esta provincia.

\section{Oferta de productos turísticos de la PSE}

En función del análisis realizado sobre los productos turísticos encontrados en la información documental y la clasificación del MINTUR, se tiene que la PSE está conformada por seis tipos de productos, siendo estos: Turismo Cultural; Ecoturismo; Turismo de Naturaleza; Turismo de Deporte y Aventura; Turismo Comunitario; Sol y Playa (ver Tabla 5).

Tabla 5.

Ubicación de los tipos de productos turísticos naturales y culturales de la PSE

\begin{tabular}{|c|c|c|c|c|c|c|}
\hline Ubicación & $\begin{array}{l}\text { Turismo } \\
\text { Cultural }\end{array}$ & $\begin{array}{l}\text { Ecoturismo/ } \\
\text { Turismo de } \\
\text { Naturaleza }\end{array}$ & $\begin{array}{c}\text { Turismo de } \\
\text { deporte y } \\
\text { Aventura }\end{array}$ & $\begin{array}{c}\text { Turismo } \\
\text { Comunitario }\end{array}$ & $\begin{array}{l}\text { Sol y } \\
\text { Playa }\end{array}$ & Ponderado \\
\hline Ancón & 1 & 1 & 0 & 0 & 0 & 0.4 \\
\hline Anconcito & 0 & 0 & 1 & 0 & 1 & 0.4 \\
\hline Ayangue & 0 & 0 & 1 & 0 & 1 & 0.4 \\
\hline Capaes & 0 & 0 & 1 & 0 & 1 & 0.4 \\
\hline Islote El Pelado & 0 & 1 & 1 & 0 & 1 & 0.6 \\
\hline Libertador Bolivar & 0 & 0 & 0 & 0 & 1 & 0.2 \\
\hline Loma Alta & 0 & 1 & 0 & 0 & 0 & 0.2 \\
\hline Manglaralto (Dos Mangas) & 0 & 1 & 0 & 0 & 0 & 0.2 \\
\hline Mar Bravo & 0 & 1 & 0 & 0 & 0 & 0.2 \\
\hline Montañita & 0 & 0 & 1 & 0 & 1 & 0.4 \\
\hline Olón & 0 & 0 & 1 & 0 & 1 & 0.4 \\
\hline Playa Bruja & 0 & 0 & 1 & 0 & 1 & 0.4 \\
\hline Punta Carnero & 0 & 0 & 1 & 0 & 1 & 0.4 \\
\hline Salinas & 0 & 0 & 1 & 0 & 1 & 0.4 \\
\hline Salinas (FAE-Chocolatera) & 0 & 1 & 1 & 0 & 1 & 0.4 \\
\hline Salinas (Paco Illescas) & 0 & 0 & 1 & 0 & 1 & 0.4 \\
\hline San Biritute & 1 & 1 & 0 & 1 & 0 & 0.6 \\
\hline San Pablo & 0 & 0 & 0 & 0 & 1 & 0.2 \\
\hline Santa Elena & 1 & 0 & 0 & 0 & 0 & 0.2 \\
\hline Valdivia & 1 & 0 & 0 & 1 & 0 & 0.4 \\
\hline Cantidad & 4 & 7 & 11 & 2 & 13 & \\
\hline
\end{tabular}

Fuente: Elaboración propia a partir de Perrone et al., 2009; GAD Cantonal Salinas, 2014; MINTUR, 2007; MINTUR, 2009 
Entre estos productos el que más incidencia tiene en el territorio es el turismo de sol y playa, el que se consume en todas las localidades y comunas que conforman la PSE, seguido de cerca está el producto de Turismo de Deporte y Aventura, debido a las características biofísicas que lo constituyen. Por otro lado, el tipo de producto que menos se consume es el de Turismo Cultural, esto a pesar de la importancia arqueológica y etnográfica del territorio.

Entre los lugares donde se consume más de un solo tipo de producto turístico en la PSE se encuentran Islote El Pelado y San Biritute (ver Tabla 5), el primero una pequeña isla en el Océano Pacifico y el otro una comuna ubicada en la parte rural interior de la península.
Estos productos turísticos en términos de promoción son considerados "Productos Estrella" entre los que se encuentran el Ecoturismo, Turismo de Naturaleza y el Turismo de Deporte y Aventura, pero por la vocación turismo de Sol y Playa no reciben atención para su promoción, por lo que, está pendiente el desarrollo y/o fortalecimiento de nuevos productos.

\section{Evolución del Producto turístico de la PSE}

Los productos turísticos de la PSE han evolucionado de una propuesta inicial de turismo de Sol y Playa, en donde se tomaba ventaja de la posición geográfica de la provincia, hasta ofertar productos tales como: turismo de deporte y aventura, turismo cultural, ecoturismo, turismo de naturaleza y turismo comunitario (ver Figura 2).

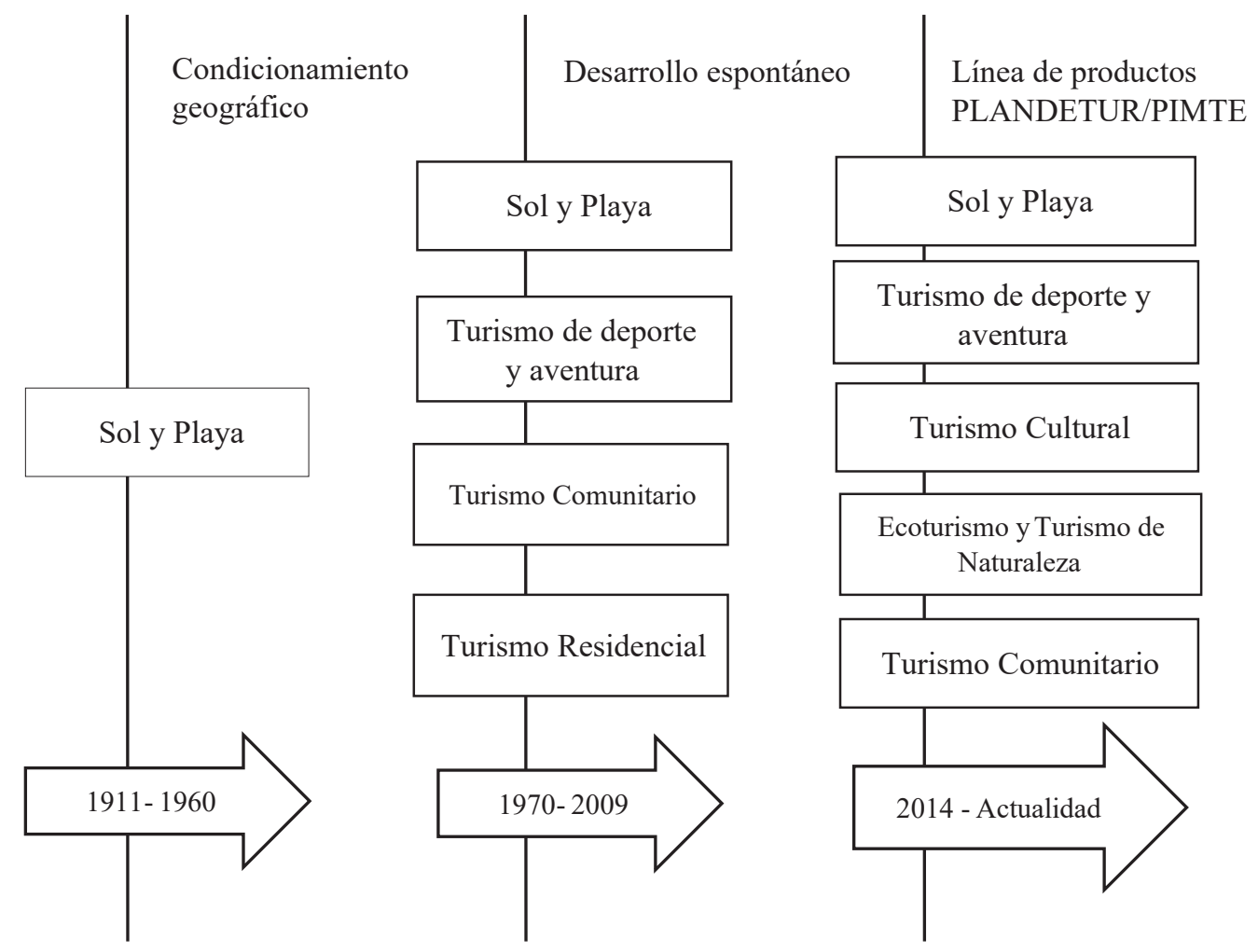

Figura 2. Salida semestral de ministros. Total, Ministerios Estudio. Fuente: Elaboración propia. 


\section{Análisis FODA}

El análisis FODA (ver Tabla 6) ha sido realizado en base a las variables tangibles e intangibles mencionadas en la revisión de la literatura del estudio: atractivo turístico, planta turística, servicios complementarios e infraestructura.
De lo cual se infiere que la PSE como destino presenta varios aspectos que aportan al desarrollo turístico como el mejoramiento de la infraestructura (sistema de transporte terrestre y aéreo, carreteras), implementación de servicios complementarios (centros comerciales con servicios varios), escenarios naturales

Tabla 6.

Análisis FODA de los destinos turísticos de la PSE en función de variables tangibles e intangibles

\begin{tabular}{|c|c|c|c|c|}
\hline & FORTALEZAS & DEBILIDADES & OPORTUNIDADES & AMENAZAS \\
\hline 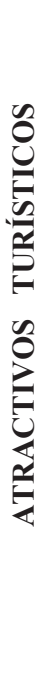 & $\begin{array}{l}\text {-Presencia de áreas } \\
\text { protegidas (marino- } \\
\text { costera, manglar, } \\
\text { bosque seco y bosque } \\
\text { húmedo tropical). } \\
\text {-Variedad de líneas de } \\
\text { productos (Sol y Playa, } \\
\text { Cultural, Eco-turismo, } \\
\text { Deportes, Turismo } \\
\text { comunitario). } \\
\text { •Forma parte de rutas } \\
\text { regionales como la del } \\
\text { Spondylus o Surf. } \\
\text { •La gastronomía es uno } \\
\text { de los elementos más } \\
\text { valorados por los } \\
\text { visitantes. }\end{array}$ & $\begin{array}{l}\text {-Visita de atractivos de } \\
\text { sol y playa está marcado } \\
\text { por la estacionalidad. } \\
\text { •Baja valoración del } \\
\text { patrimonio cultural y el } \\
\text { turismo comunitario por } \\
\text { parte de los locales. } \\
\text { •Deterioro de los } \\
\text { ecosistemas vinculados } \\
\text { a los atractivos naturales } \\
\text { causada por presión } \\
\text { antrópica que causa el } \\
\text { turismo. }\end{array}$ & $\begin{array}{l}\text {-Atractivos turísticos } \\
\text { ideales para el } \\
\text { desarrollo de eventos } \\
\text { internacionales } \\
\text { (competencias de } \\
\text { deporte extremos como } \\
\text { el surf, conciertos o } \\
\text { festivales). } \\
\text {-Impulso de nuevas } \\
\text { actividades diseñadas } \\
\text { para el turista de aventura } \\
\text { (parapente, snorkel, } \\
\text { buceo, entre otras). } \\
\text {-Potencial para el } \\
\text { desarrollo de nuevos } \\
\text { turismos: turismo } \\
\text { náutico, turismo marino } \\
\text { costero. }\end{array}$ & $\begin{array}{l}\text {-Ampliación de zonas } \\
\text { agrarias o explotación } \\
\text { industrial merma el } \\
\text { ecosistema. } \\
\text {-Presencia de productos } \\
\text { similares en provincias } \\
\text { aledañas con mejor } \\
\text { difusión. } \\
\text { •Desastres naturales por } \\
\text { terremotos y/o aguajes. }\end{array}$ \\
\hline 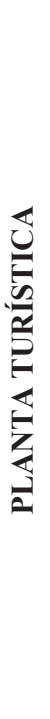 & $\begin{array}{l}\text {-Sector de alojamiento y } \\
\text { alimentación está } \\
\text { liderada por } \\
\text { medinas/pequeñas } \\
\text { empresas de propiedad } \\
\text { de personas de la } \\
\text { localidad. } \\
\text { •Servicio de transporte } \\
\text { interprovincial eficiente. } \\
\text {-Los visitantes valoran } \\
\text { la ubicación de los } \\
\text { alojamientos. }\end{array}$ & $\begin{array}{l}\text {-Informalidad de los } \\
\text { servicios turísticos y } \\
\text { poca profesionalización } \\
\text { de prestadores de } \\
\text { servicios turísticos. } \\
\text {-Transporte público } \\
\text { urbano e intercantonal } \\
\text { deficiente. } \\
\text { •Oferta alojamiento y } \\
\text { alimentos deficiente en } \\
\text { temporada alta. } \\
\text { •Participación asociativa } \\
\text { deficiente para enfrentar } \\
\text { la estacionalidad y } \\
\text { temporalidad. }\end{array}$ & $\begin{array}{l}\text {-Oferta de carreras } \\
\text { universitarias o } \\
\text { capacitaciones por } \\
\text { competencias en } \\
\text { materia turística. } \\
\text {-Impulso de créditos } \\
\text { para el desarrollo de } \\
\text { proyectos turísticos a } \\
\text { través de bancos } \\
\text { estatales. } \\
\text {-Organización de } \\
\text { eventos en temporada } \\
\text { baja. } \\
\text {-Visitantes de la región } \\
\text { andina disminuyen el } \\
\text { impacto económico en } \\
\text { la temporada baja. }\end{array}$ & $\begin{array}{l}\text {-Hoteles y restaurantes } \\
\text { de mayor categoría en } \\
\text { provincias aledañas. } \\
\text {-Presencia de } \\
\text { comerciantes informales } \\
\text { de otros cantones o } \\
\text { provincias en temporada } \\
\text { alta. } \\
\text {-Presencia de } \\
\text { transportistas informales } \\
\text { de otros cantones o } \\
\text { provincias en temporada } \\
\text { alta. } \\
\text {-Competencia desleal } \\
\text { por alquiler de } \\
\text { viviendas de segunda } \\
\text { residencia que compiten } \\
\text { con el sector } \\
\text { alojamiento formal. }\end{array}$ \\
\hline
\end{tabular}

Fuente: Elaboración propia. 
Rafael Francisco Arce Bastidas, Erick Suárez Domínguez, Elisa Verónica Solís Argandoña, Nadia Argudo Guevara

Tabla 6.

Análisis FODA de los destinos turísticos de la PSE en función de variables tangibles e intangibles

\begin{tabular}{|c|c|c|c|c|}
\hline & FORTALEZAS & DEBILIDADES & OPORTUNIDADES & AMENAZAS \\
\hline 象 & $\begin{array}{l}\text {-Servicios bancarios } \\
\text { eficientes en la cabecera } \\
\text { cantonal. } \\
\text {-Elaboración y } \\
\text { comercialización de } \\
\text { artesanías con productos } \\
\text { locales. } \\
\text {-Centros comerciales } \\
\text { con infraestructura } \\
\text { adecuada en la cabecera } \\
\text { cantonal. }\end{array}$ & $\begin{array}{l}\text {-Centros de atención } \\
\text { médicos limitados. } \\
\text { •Pocas áreas verdes, } \\
\text { recreativas y deportivas } \\
\text { en el cantón Santa } \\
\text { Elena. } \\
\text {-Servicios bancarios } \\
\text { deficientes en } \\
\text { parroquias rurales. }\end{array}$ & $\begin{array}{l}\text {-Inauguración de nueva } \\
\text { plataforma para el } \\
\text { desarrollo de eventos a } \\
\text { través del malecón de } \\
\text { Ballenita. } \\
\text {-Implementación de } \\
\text { señalética turística por } \\
\text { parte del gobierno } \\
\text { central. }\end{array}$ & $\begin{array}{l}\text { - Presencia de } \\
\text { comerciantes informales } \\
\text { de otros cantones o } \\
\text { provincias en temporada } \\
\text { alta. } \\
\text {-Cadenas de comida } \\
\text { rápida desplazan la } \\
\text { gastronomía local. }\end{array}$ \\
\hline 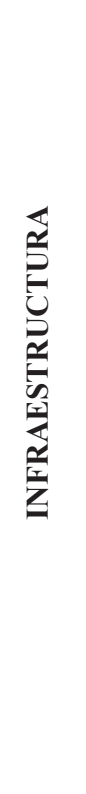 & $\begin{array}{l}\text {-Carreteras de primer } \\
\text { orden en buenas } \\
\text { condiciones. } \\
\text { •Cobertura de servicios } \\
\text { de internet o telefonía } \\
\text { móvil eficiente en la } \\
\text { cabecera cantonal. } \\
\text {-Nuevas obras de } \\
\text { regeneración urbana en } \\
\text { malecones y muelles de } \\
\text { Salinas, Ballenita, } \\
\text { Montañita. } \\
\text {-Terminal terrestre } \\
\text { regional Sumpa } \\
\text { localizado en el cantón } \\
\text { Santa Elena. } \\
\text {-Aeropuerto doméstico } \\
\text { General Ulpiano Páez }\end{array}$ & $\begin{array}{l}\text {-Déficit en la co-bertura } \\
\text { de telecomunicaciones } \\
\text { especialmente en la } \\
\text { parroquia rural de } \\
\text { Simón Bolívar. } \\
\text {-Deficiente abastecimiento } \\
\text { de servicios básicos } \\
\text { zonas rurales. } \\
\text {-Demora en el } \\
\text { mantenimiento y } \\
\text { renovación vial. } \\
\text { •Deficiencia de } \\
\text { ciclovías en el cantón. } \\
\text { •Colapso de servicios } \\
\text { básicos en temporada alta. } \\
\text {-Escasa red de } \\
\text { alcantarillado para } \\
\text { zonas residenciales. } \\
\text { •Bajo mantenimiento de } \\
\text { calles en las periferias de } \\
\text { los atractivos turísticos. }\end{array}$ & $\begin{array}{l}\text { •Rehabilitación y } \\
\text { construcción del sistema } \\
\text { vial Chongón-Santa } \\
\text { Elena. } \\
\text {-Aeropuerto } \\
\text { Internacional cercano al } \\
\text { cantón Santa Elena que } \\
\text { facilita la accesibilidad } \\
\text { de visitantes } \\
\text { extranjeros. }\end{array}$ & $\begin{array}{l}\text { - Aislamiento de } \\
\text { comunidades de zonas } \\
\text { rurales y vinculadas a la } \\
\text { actividad turística en } \\
\text { época de invierno. } \\
\text { - Mal manejo de los } \\
\text { dineros recaudados por } \\
\text { el cobro de peaje para el } \\
\text { mantenimiento y } \\
\text { construcción de nuevas } \\
\text { obras viales } \\
\text {-Deficiente seguridad } \\
\text { peatonal en las } \\
\text { carreteras interurbanas y } \\
\text { parroquiales (pasos } \\
\text { peatonales). } \\
\text {-Interrupción de } \\
\text { servicios e } \\
\text { infraestructura por } \\
\text { terremotos y/o aguajes. }\end{array}$ \\
\hline
\end{tabular}

Fuente: Elaboración propia.

con potencial para la organización de eventos internacional, obras y gestión del gobierno central que aportan a la fuerza turística del sector. Sin embargo, hay elementos que al no estar bien concebidos se vuelven una barrera para el fortalecimiento de este sector, identificando en líneas generales la ausencia de mecanismos de control efectivos a la informalidad, sistema de servicios públicos poco eficientes para soportar los efectos de la temporalidad y estacionalidad, escaso trabajo colaborativo o asociativo por parte de actores claves en la industria, crecimiento acelerado de la competencia (calidad, precios, costos, estructuración del producto, características del producto, promoción, etc.), entre otros factores que han desacelerado el crecimiento de este destino turístico.

En este contexto, la autonomía por parte del gobierno local de la PSE ha permitido avances importantes en materia turística, pero se ha visto condicionados por la carencia de políticas claras, 
Tabla 6.

Análisis FODA de los destinos turísticos de la PSE en función de variables tangibles e intangibles

\begin{tabular}{|c|c|c|c|c|}
\hline & FORTALEZAS & DEBILIDADES & OPORTUNIDADES & AMENAZAS \\
\hline 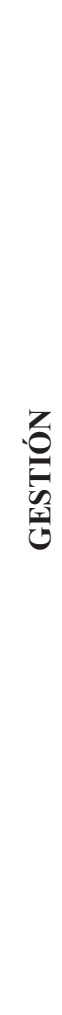 & $\begin{array}{l}\text {-Auto organización } \\
\text { permite el desarrollo } \\
\text { turístico. } \\
\text {-Desconcentración y } \\
\text { descentralización de las } \\
\text { decisiones de los } \\
\text { municipios en asuntos } \\
\text { turísticos. }\end{array}$ & $\begin{array}{l}\text { •No existe } \\
\text { involucramiento de todos } \\
\text { los actores sociales en la } \\
\text { toma de decisiones. } \\
\text { • No existen normas para } \\
\text { la regulación de viviendas } \\
\text { de segunda residencia. } \\
\text { - Limitada planificación } \\
\text { del destino vinculado a } \\
\text { la conservación y la } \\
\text { sostenibilidad. } \\
\text {-Ineficacia de los planes } \\
\text { de evacuación el caso } \\
\text { de la ocurrencia de } \\
\text { algún desastre natural. } \\
\text { - Limitada promoción de } \\
\text { los atractivos y servicios } \\
\text { turísticos. } \\
\text { - Grupos informales } \\
\text { tienen más poder sobre } \\
\text { las decisiones en turismo } \\
\text { que los organismos } \\
\text { formales. } \\
\text { •No existe un estudio } \\
\text { sobre la demanda oficial. } \\
\text { •Bajo nivel de } \\
\text { educación. }\end{array}$ & $\begin{array}{l}\text {-Desarrollo de mesa de } \\
\text { trabajo coordinado } \\
\text { desde los organismos } \\
\text { públicos. } \\
\text { correspondientes. } \\
\text { - Turismo es un sector } \\
\text { priorizado en la } \\
\text { planificación nacional. }\end{array}$ & $\begin{array}{l}\text {-No existe presupuesto } \\
\text { para promoción de la } \\
\text { PSE ya que es considerado } \\
\text { un producto de } \\
\text { oportunidad para el } \\
\text { gobierno. } \\
\text {-Desastres naturales por } \\
\text { terremotos y aguajes. } \\
\text {-Delincuencia por } \\
\text { personas ajenas a las } \\
\text { comunidades. }\end{array}$ \\
\hline
\end{tabular}

Fuente: Elaboración propia.

creando así dos espacios bastante definidos: el de los turistas con servicios básicos y áreas turísticas más o menos adecuadas y el de los residentes con servicios y áreas públicas poco eficientes para su abastecimiento. Asimismo, este mismo vacío impacta sobre otros aspectos como la toma de decisiones y su organización interna lo que no le permite desarrollar un turismo sostenible.

\section{Conclusiones}

La implicación académica que resulta del estudio es la necesidad de poder definir un concepto de producto turístico, ya que su definición supone ambigüedades.
Esto a pesar de que existen organismos públicos nacionales e internacionales que han trabajado sobre la cuestión, lo cual denota que no se ha encontrado un consenso en este tema, haciéndose imperioso el desarrollo de una taxonomía que pueda ser utilizada ampliamente en el ámbito turístico o al menos a nivel país.

Los resultados reflejan que la PSE por su condicionamiento geográfico ha sido encasillado como un producto clásico de Sol y Playa, esto desde inicio del siglo XX. A pesar de los esfuerzos por asociarlo a los nuevos turismos como son el cultural y el de aventura en años recientes, aún la PSE es un espacio para 
el disfrute únicamente de sol y playa.

Por otro lado, los productos turísticos actuales de la PSE son el resultado del desarrollo espontáneo del turismo. Parte de este resultado se debe a la presión inmobiliaria a la que de poco se le unieron empresas de servicio como alojamiento y el sector de A\&B. Por otro lado, está la presencia de una gestión pública intermitente que no logra regularizar la actividad turística pese a los avances sobre ordenamiento y políticas territoriales que posee la PSE. Esto ha conducido a un bajo direccionamiento de los procesos de regulación y control, promoción y difusión y un escaso perfeccionamiento del recurso humano. A esta realidad debe sumarse la saturación y explotación indiscriminada de atractivos turísticos estacionales, como el avistamiento de ballenas jorobadas y el uso recreativo de la playa en los feriados de fin de año y carnaval. Lo que ha generado sector turístico caótico, con servicios turísticos informales, especulación, deterioro $\mathrm{y}$ explotación descontrolada de los recursos y ecosistemas litorales de la península (CADS-ESPOL, 2013; Empresa Pública del Agua, 2014; GAD Cantonal Salinas, 2014; GAD Santa Elena, 2014).

En consecuencia, sin una clara oferta no es posible comercializar la PSE a nuevos segmentos de mercados. Por lo que es necesario el desarrollo del destino, que más allá de la adaptación de los productos turísticos, estructure productos que impliquen la valorización social de los atractivos a fin de poder organizar tipologías de turismo e implementar productos turísticos más sostenibles y respetuosos con el medio ambiente que busquen la participación de los diferentes agentes sociales.

Las limitaciones del estudio están dadas por la cantidad y calidad de información disponible sobre la PSE, y la poca claridad en la definición de producto turístico. Por lo que, es necesario estudios complementarios sobre la caracterización y percepción de producto turístico, así como temas relacionados a las motivaciones y preferencias sobre mercados emergentes que cada vez viajan más y cuya fragmentación como mercado presiona a la reinvención de los destinos de sol y playa.

\section{Referencias}

Acerenza, M. A. (2004). Fundamentos de Marketing Turístico. México: Trillas.

CADS-ESPOL. (2013). Proyecto de evaluación de vulnerabilidad y reducción de riesgos de desastres a nivel municipal en el Ecuador. Documento preliminar. Obtenido de http://repositorio.cedia.org.ec/bitstream/1 23456789/859/1/Perfil\%20territorial\%20 SANTA\%20ELENA.pdf

Cárdenas, F. (2008). Producto Turístico: aplicación de la estadística y del muestreo para su diseño. México: Trillas.

Carvache, M., Carvache, W., Macas, C., y Orden, M. (2018). Motivaciones, Valoración y Satisfacción del Turista en un destino de Sol y Playa de Ecuador. Revista Espacios, 39(13), 4.

Carvache, W., Torres, M. y Carvache, M. (2017). Análisis del perfil y satisfacción del turista que visita Montañita-Ecuador. Cuadernos de Turismo, (39), 113-129. Doi: 10.6018/turismo.39.290461 
CEPAL (2015). Análisis de la Cadena del Turismo. Comisión Económica para América Lati-na y el Caribe. Obtenido de https://www.vicepresidencia.gob.ec/wp-c ontent/ploads/2015/07/Resumen-CadenaTurismo-1.pdf.

Empresa Pública del Agua. (2014). Proyecto trasvase desde canal Chongón-Sube y Baja a la Presa San Vicente en el cantón Santa Elena de la provincia de Santa Elena. Obtenido de http://www.empresaagua. gob.ec/wp-content/uploads/downloads/2 018/04/Perfil-Proyecto-Chong\%C3\%B3 n-San-Vicente.pdf

Forteza, J. J., Lam, Y., y Ledesma, J. (2017). Motivación, satisfacción e intenciones del turista náutico en la Ruta del Spondylus (Ecuador). Estudios y perspectivas en turismo, 26(2), 267-285.

GAD Cantonal Salinas. (2014). Plan de desarrollo y ordenamiento territorial del Cantón Salinas. Obtenido de http://app.sni.gob. ec/sni-link/sni/PORTAL_SNI/data_sigad plus/sigadplusdiagnostico/DIAGNOSTI CO\%20PDOT\%202014_13-11-2014.pdf

GAD Cantonal Santa Elena (2014). Plan de Desarrollo y Ordenamiento Territorial Provincial 2015-2019. Obtenido de http://app.sni.gob.ec/sni-link/sni/PORTA L_SNI/data_sigad_plus/sigadplusdocum entofinal $/ 0968580510001 \_$PDyOT $\% 20 \%$ 20SANTA\%20ELENA\%20DOCUMEN TO_FINAL_16-05-2016_09-31-46.pdf

GAD Provincial de Santa Elena. (2015). Resumen Ejecutivo Plan de Desarrollo y Ordenamiento Territorial Provincial 2015-2019. Gobierno Autónomo Descentralizado Mu-nicipal de Santa Elena. Recuperado de: http://app.sni.gob. ec/sni-link/sni/PORTAL_SNI/data_sigad _plus/sigadplusdocumentofinal/0968580 510001_Resumen\%20Ejecutivo_PDOT $\%$ 20SANTTA\%20ELENA\%202015_14-0 8-2015_16-21-31.pdf
Ibáñez, R., y Rodríguez, I. (2012). Tipologías y antecedentes de la actividad turística: turismo tradicional y turismo alternativo. En A. Ivanova y R. Ibáñez (Ed.), Medio ambiente y política turística en México, (pp. 17-33). México: Secretaría de Medio Ambiente y Recursos Naturales.

Ibarra, J. (2001). Análisis de la oferta de turismo cultural en España. Estudios turísticos, (150), 15-40.

INEC. (2010). Fascículo Provincial Santa Elena. Resultados del Censo 2010 de población y vivienda en el Ecuador. Recuperado de http://www.ecuadorencifras.gob.ec/wp-c ontent/descargas/Manu-lateral/Resultado s-provinciales/santa_elena.pdf

Jefferson, A., y Lickorish, L. (1991). Marketing tourism: A practical guide. Londres: Longman Publishing Group.

Lafuente Ibáñez, C., y Marín Egoscozábal, A. (2008). Metodologías de la investigación en las ciencias sociales: Fases, fuentes y selección de técnicas. Revista Escuela de Administración de Negocios, (64), 5-18.

Lambogglia, J. C. (2014). Análisis del turismo y su importancia en el crecimiento económico en América Latina: el caso del Ecuador (Tesis de Maestría). Flacso, Quito-Ecuador.

León, V. (2013). Aproximación al turismo residencial en la provincia de Santa Elena, Ecuador. Retos, 3(6), 127-138. https://doi.org/10. 17163/ret.n6.2013.01

Mankiw, N. G. (2017). Principios de Economía (Séptima Edición). México, D.F.: Cengage Learning.

Martínez, D. (2014). El turismo y su impacto económico en el sector hotelero del cantón Salinas. Provincia de Santa Elena período 2009-2011 (Tesis de Maestría). Universidad de Guayaquil. Guayaquil, Ecuador. 
McKercher, B. (2016). Towards a taxonomy of tourism products. Tourism Management, (54), 196-208. https://doi.org/10.1016/j. tourman.2015.11.008

Medlik, S., y Middleton, V. T. (1973). The product formulation in tourism. Tourism and marketing, 13. Berne: AIEST.

Middleton, U. (1989). Tourist product. En S.F. Witt y L. Moutinho (Eds.), Tourism Marketing and Management Handbook, (pp. 572-576). Londres: Prentice Hall.

Milio, I. (2004). Diseño y comercialización de productos turísticos locales y regionales: hostelería y turismo. Madrid: ThomsonParaninfo.

MINTUR. (2007). Diseño del Plan Estratégico de Desarrollo de Turismo Sostenible para Ecuador "PLADENTUR 2020". Recuperado de https://www.turismo.gob. ec/wp-content/uploads/downloads/2013/ 02/PLANDETUR-2020.pdf

MINTUR. (2009). Plan Integral de Marketing Turístico de Ecuador PIMTE 2014. Recuperado de http://www.competencias. gob.ec/wp-content/uploads/2017/06/c.-2 014.-PLAN-INTEGRAL-MARKETING -TURISTICO.pdf

MINTUR. (2012). La experiencia turística en el Ecuador, cifras esenciales de turismo interno y receptor. Recuperado de https://docplayer.es/17158333-La-experi encia-turistica-en-el-ecuador-cifras-esenc iales-de-turismo-interno-y-receptorr.html

MINTUR. (2013). Proyecto Ecuador Potencia Turística. Recuperado de: https://www. turismo.gob.ec/wp-content/uploads/2015 /05/Documento-Proyecto-Ecuador-Poten cia-Tur\%C3\%ADstica.pdf

MINTUR. (2015). Ecuador invita al mundo a vivir $y$ sentir. Recuperado de http://www.turis mo.gob.ec/ecuador-invita-al-mundo-a-vi vir-y-sentir/
MINTUR. (2018). Arribo de turistas a Ecuador creció en $14 \%$ en 2017 . Recuperado de https://www.turismo.gob.ec/arribo-de-tur istas-a-ecuador-crecio-en-14-en-2017/

Panagiotou, G. (2003). Bringing SWOT into focus. Business Strategy Review, 14(2), 8-10. Doi: 10.1111/1467-8616.00253

Perrone, A., Cajiao, D., y Burgos, M. (2009). Turismo de naturaleza en la zona marino costera del Ecuador continental. Conservación Internacional Ecuador, Ministerio del Ambiente del Ecuador, Ministerio de Turismo del Ecuador. Guayaquil, Ecuador.

Pizam, A., Neumann, Y., y Reichel, A. (1978). Dimentions of tourist satisfaction with a destination area. Annals of Tourism Research, 5(3), 314-322.

Prieto, M. (2011). Los estudios sobre turismo en Ecuador. En M. Prieto (Ed.), Espacios en disputa: el turismo en Ecuador, (pp. 9-28). FLACSO Ecuador.

Revilla, M. A., Gil, J., López, J. M., y Rey, M. (2004). Fundamentos de marketing turístico. Madrid: Editorial Síntesis.

Salinas, E., y Medina, N. (2009). Los productos turísticos, pilares de la comercialización: Dos ejemplos del centro histórico de la Habana, Cuba. Estudios y perspectivas en turismo, 18(2), 227-242.

Schilling, J. (2006). On the pragmatics of qualitative assessment: Designing the process for content analysis. European Journal of Psychological Assessment, 22(1), 28-37. Doi: /10.1027/1015-5759.22.1.28

SERNATUR. (2015). Manual paso a paso para el diseño de productos turísticos integrados. Recuperado de https://asesoresenturismo peru.files.wordpress.com/2016/08/244-m anual-productos-turc3adsticos-chile.pdf

Smith, S. L. (1994). The tourism product. Annals 
of Tourism Research, 21(3), 582-595.

Stothert, K. E. (1985). The preceramic Las Vegas culture of coastal Ecuador. American Antiquity, 50(3), 613-637. https:// doi.org/10.2307/280325

UNWTO. (2017). Panorama OMT del Turismo Internacional. Recuperado de https:// www.e-unwto.org/doi/pdf/10.18111/9789 284419043

UNWTO (2018). Glosario de términos de turismo. Recuperado de https://www.unwto.org/ es/glosario-terminos-turisticos

UNWTO/ETC. (2011). Handbook on Tourism Product Development. Recuperado de https://www.e-unwto.org/doi/book/10.18 111/9789284413959.

Villagómez, C., Campoverde, C., y Arteaga, M. (2018). Análisis de la demanda turística desde el punto de vista de la motivación y satisfacción de su gastronomía. El caso Salinas (Ecuador). HOLOPRAXIS, 2(1), 225-249. 
